Canadian Journal of Fisheries and Aquatic Sciences

Canadian

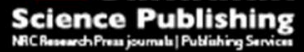

Journal canadien des sciences halieutiques et aquatiques

\title{
Estimation of occupancy, density, and abundance of larval lampreys in tributary river mouths upstream of dams on the Columbia River, Washington and Oregon
}

\begin{tabular}{|r|l|}
\hline Journal: & Canadian Journal of Fisheries and Aquatic Sciences \\
\hline Manuscript ID & cjfas-2016-0212.R1 \\
\hline Manuscript Type: & Article \\
\hline Date Submitted by the Author: & 27-Sep-2016 \\
\hline Complete List of Authors: & $\begin{array}{l}\text { Harris, Julianne E.; U.S. Fish and Wildlife Service, Columbia River Fish and } \\
\text { Wildlife Conservation Office } \\
\text { Jolley, Jeffrey C.; U.S. Fish and Wildlife Service, Columbia River Fish and } \\
\text { Wildlife Conservation Office }\end{array}$ \\
\hline Keyword: & $\begin{array}{l}\text { Zero-inflated N-mixture model, Bayesian, Entosphenus tridentatus and } \\
\text { Lampetra, deepwater electrofishing, DAMS < Environment/Habitat }\end{array}$ \\
\hline
\end{tabular}


1 Estimation of occupancy, density, and abundance of larval lampreys in tributary river

2 mouths upstream of dams on the Columbia River, Washington and Oregon

4 Julianne E. Harris (Corresponding author)

5 U.S. Fish and Wildlife Service, Columbia River Fish and Wildlife Conservation Office, 1211 SE

6 Cardinal Court, Suite 100, Vancouver, WA 98683, USA

7 Email: julianne_harris@fws.gov

8 Telephone number: $360-604-2551$

9 Fax number: 360-604-2505

10

11 Jeffrey C. Jolley

12 U.S. Fish and Wildlife Service, Columbia River Fish and Wildlife Conservation Office, 1211 SE

13 Cardinal Court, Suite 100, Vancouver, WA 98683, USA

14 Email: jeffrey_jolley@,fws.gov

15 
16 Abstract: We estimated occupancy, density, and abundance of larval Pacific lamprey

17 (Entosphenus tridentatus) and Lampetra spp. in tributary river mouths to impounded portions of

18 the Columbia River, Washington and Oregon, using count data from deepwater electrofishing.

19 Count data were analyzed by Bayesian methods using zero-inflated N-mixture models modified

20 to include our experimentally-derived estimate of capture probability of $0.70(95 \%: 0.63-0.77)$.

21 Lampetra spp. were only collected in river mouths in Bonneville Reservoir, while Pacific

22 lamprey were also captured from river mouths in The Dalles and John Day reservoirs. In

23 occupied river mouths, average densities were commonly $0.2-0.3 \cdot \mathrm{m}^{-2}$, but ranged from $0.18 \cdot \mathrm{m}^{-}$

242 to $1.72 \cdot \mathrm{m}^{-2}$ for Pacific lamprey and $0.24 \cdot \mathrm{m}^{-2}$ to $1.72 \cdot \mathrm{m}^{-2}$ for Lampetra spp. Although there was

25 spatial overlap, estimated density peaked in the Klickitat River mouth (556 600 larvae) for

26 Pacific lamprey and in the Wind River mouth (544 800 larvae) for Lampetra spp. Our study

27 demonstrates considerable larval rearing in river mouths to impounded portions of the Columbia

28 River; however, information on survival is needed to evaluate the contribution of this production

29 to population growth and conservation. 


\section{Introduction}

World-wide, lampreys have experienced population declines (Renaud 1997; Maitland et al. 2015). A species of particular conservation concern is the anadromous Pacific lamprey (Entosphenus tridentatus) (Close et al. 2002; Wang and Schaller 2015). Pacific lamprey import and cycle nutrients in freshwater ecosystems and are prey for marine and freshwater predators (Beamish 1980; Close et al. 2002; Riemer et al. 2011). They are also important to Native American tribes for subsistence, spiritual, and medicinal purposes (Close et al. 2002; Wang and Schaller 2015; Noble et al. 2016). Pacific lamprey were historically distributed from Mexico to Japan (Ruiz-Campos and Gonzalez-Guzman 1996; Yamazaki et al. 2005); however, they do not exhibit natal homing and there is only limited genetic differentiation over their range (Goodman et al. 2008; Spice et al. 2012). The Columbia River Basin may serve as a region of high production for Pacific lamprey and therefore may be important for conservation of the species (Keefer et al. 2013; McIlraith et al. 2015). A better understanding of distribution and density of larval Pacific lamprey in the heavily modified Columbia River Basin would help identify and characterize larval rearing habitat and the potential value of spawning upstream of dams.

Similar freshwater habitat preferences have been documented for larvae of multiple lampreys (Slade et al. 2003; Smith et al. 2011; Ferreira et al. 2013; Aronsuu and Virkkala 2014). Once Pacific lamprey develop beyond the swim-up stage, larvae burrow and filter feed in fine sand when it is available (Torgersen and Close 2004; Stone and Barndt 2005). Larvae regularly disperse, usually moving in a downstream direction (Moser et al. 2015b). After the larval stage, Pacific lamprey metamorphose into juveniles and migrate to the Pacific Ocean where they are parasitic until they reach sexual maturity (Beamish 1980; Dawson et al. 2015). Larval western brook lamprey (Lampetra richardsoni) which are river resident, and larval river lamprey 
53 (Lampetra ayresii) which are anadromous, are also found burrowed in fine sediments in the

54 Columbia River Basin. To date, most larval lamprey sampling has been completed in wadeable

55 streams (Moser et al. 2007). Although use of non-wadeable areas by larval sea lamprey

56 (Petromyzon marinus) has been documented (Bergstedt and Genovese 1994; Lee and Weise

57 1989; Fodale et al. 2003), use by larvae of other lamprey species has received little study; it has

58 been suggested that future research is needed to evaluate the importance of deeper-water habitat

59 for lamprey rearing and production (Jolley et al. 2012; Dawson et al. 2015).

Our study quantified use of tributary river mouths in impounded areas of the Columbia

61 River by larval lampreys. There are 14 large dams on the mainstem Columbia and Snake rivers

62 that provide fish passage. Although Pacific lamprey and Lampetra spp. have been collected

63 upstream of the fourth dam, McNary Dam (Moser and Close 2003; Meeuwig et al. 2005; Grote

64 et al. 2014), larval use of tributary river mouths in impounded areas has not been studied. We

65 sampled for larval lampreys using a deepwater electrofishing method designed by Bergstedt and

66 Genovese (1994). In soft sediments, the perimeter of the deepwater electrofisher behaves like a

67 cap, covering, stunning, and collecting burrowed lampreys in a known unit of area (Bergstedt

68 and Genovese 1994). Because the area sampled is known and sampling can be conducted at a

69 variety of depths, the deepwater electrofisher could be ideal for estimating density and

70 abundance of larval lampreys, although the probability of capturing a burrowed lamprey must be

71 incorporated into density and abundance estimation, which can be challenging. We had two

72 specific objectives: 1) experimentally estimate the probability of capturing a larval lamprey by

73 deepwater electrofishing; and 2) examine distribution and estimate the probability of occupancy,

74 density, and abundance of larval Pacific lamprey and Lampetra spp. in tributary river mouths

75 entering impounded portions of the Columbia River. 
77 Methods

78 Study site

79 We sampled for larval lampreys in river mouths of most substantial tributaries entering

80 the four lowest reservoirs in the Columbia River: Bonneville, The Dalles, John Day, and McNary

81 (Fig. 1). Included rivers ranged in stream order (1:100 000 scale) from fourth (Little White

82 Salmon River) to seventh (Yakima River; Table 1). Fine sediments in these rivers originate in

83 the Cascade and the Blue mountain ranges of Washington and Oregon (Wydoski and Whitney

84 2003). Tributary river mouths varied temporally and spatially in terms of flows, depths, and

85 sediments due to dynamic fluvial and alluvial processes, as well as hydrosystem operations. In

86 sampled river mouths, recorded ranges were 26 to $410 \mu \mathrm{S} \mathrm{cm}^{-1}$ for ambient conductivity (average

$87=102 \mu \mathrm{S} \mathrm{cm}^{-1}$ ), 5.2 to $24.4{ }^{\circ} \mathrm{C}$ for temperature (average $=16.3{ }^{\circ} \mathrm{C}$ ), and 0.2 to $23.8 \mathrm{~m}$ for depth

88 (average $=3.4 \mathrm{~m}$ ). Five river mouths were sampled within Bonneville Reservoir, one within The

89 Dalles Reservoir, and two each within the John Day and McNary reservoirs (Table 1).

Field methods

91

We sampled for larval lampreys in tributary river mouths using a deepwater electrofisher

92 from March to November, 2011-2015. Field methods were similar to those used for sampling

93 larval Pacific lamprey in the Willamette River (Jolley et al. 2012). Each tributary river "mouth"

94 was defined by a $0.5 \mathrm{~km}$ semicircle from the point where the midchannel of the tributary

95 intersected the Columbia River based on orthophotography. A layer of 30 x $30 \mathrm{~m}$ quadrats

96 encompassing each mouth was created with ArcMap 9.3 (Environmental Systems Research

97 Institute, Redlands, California). We used a Generalized Random Tessellated Stratified (GRTS)

98 approach to select $11-38$ quadrats from each mouth in a random, spatially balanced order to 
sample each year (Stevens and Olsen 2004). In addition, in 2013, quadrats in the Klickitat and Wind rivers were sampled on up to three different dates. On each sampling date, each quadrat was sampled once by deepwater electrofishing (i.e., one drop). The deepwater electrofisher samples $0.42 \mathrm{~m}^{2}$ of sediment in one drop. The number of quadrats sampled in each tributary river mouth in each year can be found in Table 1. Deepwater electrofishing sampling techniques are described in Jolley et al. (2012).

Genetic samples confirmed each collected larval lamprey as either an Entosphenus spp. or a Lampetra spp. (Spice et al. 2011; Docker et al. 2016). Each larvae was anesthetized in a bath of buffered MS-222 (tricaine methanesulfonate, 2:1), measured for total length (TL in mm), and a two x two mm tissue sample was clipped from the caudal fin and preserved in ethanol for genetic analysis. All Entosphenus were assumed to be Pacific lamprey as there are no other known species of that genus in the area, but Lampetra spp. could be either western brook lamprey L. richardsoni or western river lamprey L. ayresii. These two Lampetra spp. are "paired species" and their larvae cannot currently be distinguished by any method (Docker 2009).

\section{Capture probability experiments}

The probability of a Pacific lamprey being captured by deepwater electrofishing was estimated experimentally at Eagle Creek National Fish Hatchery in October 2011. Fiberglass troughs were subdivided with wooden dividers into chambers $(n=23)$ that fit the electrofisher snuggly. Five to seven $\mathrm{cm}$ of sediment and then water were added to each chamber. A known number of larval Pacific lamprey were seeded into each chamber and allowed 24 hours to acclimate prior to electrofishing. Each chamber was seeded at an abundance of five or 10 individuals of one of two length classes (either $<70 \mathrm{~mm}$ TL or $>80 \mathrm{~mm} \mathrm{TL}$ ). All larvae in the experiment were collected by backpack electrofishing in North Fork Eagle Creek (Clackamas 
122 River Basin, Oregon). To estimate capture probability, the deepwater electrofisher was lowered 123 into each chamber and one drop was completed according to electrofishing methods in Jolley et 124 al. (2012). Total catch $\left(C_{i}\right)$ from the one drop was recorded for each chamber $(i)$. After one drop 125 was conducted in each chamber, sediment from all chambers was thoroughly examined to locate 126 any non-captured individuals. For analysis, the number of individuals $\left(A_{i}\right)$ in each chamber $(i)$

127 was considered the total number captured by electrofishing and those located through sediment 128 examination. It was suspected that the individuals seeded into chambers, but not captured or 129 found, had escaped or were consumed by predators during the acclimation period; these larvae 130 were removed from analysis. Capture probability $\left(p_{i}\right)$ was estimated by logistic regression:

$$
C_{i} \sim \operatorname{Binomial}\left(A_{i}, p_{i}\right)
$$

131 The logit link was used to evaluate the relationship between $p_{i}$ and two categorical covariates 132 (full model), density class: either $12 \cdot \mathrm{m}^{-2}$ or $24 \cdot \mathrm{m}^{-2}$ (i.e., 5 or 10 individuals) and length class: 133 either less than $70 \mathrm{~mm}$ TL or greater than $80 \mathrm{~mm}$ TL:

$$
\operatorname{Logit}\left(p_{i}\right)=I+b_{1}[\text { Density class }]+b_{2}[\text { Length class }]
$$

134 where $b_{1}$ and $b_{2}$ are slopes for the two categorical covariates (i.e., density class and length class, 135 respectively) and $I$ represents the intercept. We modeled capture probability as a function of all 136 combinations of the two covariates (i.e., full and reduced candidate models; See Table 2). We 137 evaluated the importance of the two covariates using the Akaike's Information Criterion (AIC) 138 and the candidate model with the lowest AIC score (i.e., appropriate tradeoff between fit and 139 complexity) was selected as the best model (Burnham and Anderson 2002).

140 Occupancy, density, and abundance estimation

We used modified zero-inflated N-mixture models to estimate occupancy and local

142 abundance of larval Pacific lamprey and Lampetra spp. in tributary river mouths in the Columbia 
143 River upstream of Bonneville Dam (Royle 2004). An N-mixture (or binomial mixture) model is

144 a hierarchical Poisson regression model. These models usually incorporate spatially and

145 temporally replicated (i.e., multiple sites and multiple surveys at those sites) counts of organisms

146 to estimate two parameters: site-specific abundances and capture probability (Royle 2004; Kéry

147 and Schaub 2012). Sites and surveys at sites are considered random interchangeable samples of

148 the area as a whole. There is an ecological process to assess spatial variability in local

149 abundance (i.e., across sites) and an observational process that usually uses replicate sites and

150 surveys to estimate capture probability (Kéry and Schaub 2012). Failure to account for the

151 observational process can bias estimates, trends, variability, and relationships (Kéry et al. 2009).

152 Zero-inflated models assess the probability of occupancy, as well as abundance, given occupancy

153 (Wenger and Freeman 2008). Similar to the zero-inflated N-mixture model described in Kéry

154 and Schaub (2012), our model for each lamprey (i.e., Pacific lamprey and Lampetra spp.) had

155 three hierarchical levels: 1) probability that a tributary river mouth (i) is occupied; 2) true

156 abundance from one electrofishing $\operatorname{drop}(j)$ given that it is in an occupied tributary river mouth

157 (i); and 3) observed count from one electrofishing drop $(j)$ in each tributary river mouth $(i)$ given

158 the true abundance in that drop and capture probability. For the first level, unobserved potential

159 occupancy in each tributary river mouth $\left(z_{i}\right)$ was estimated by a Bernoulli distribution:

$$
z_{i} \sim \operatorname{Bernoulli}(\Omega)
$$

161 Where $\Omega$ is the overall probability that a tributary mouth is occupied. For the second level, the 162 unobserved true abundance $\left(N_{i, j}\right)$ in a drop for each tributary river mouth $(i)$ and each

163 electrofishing drop $(j)$ was estimated using a Poisson distribution:

$$
N_{i, j} \sim \text { Poisson }\left(\gamma_{i, j}\right)
$$


164 Where $\gamma_{i, j}$ is effective abundance for that tributary mouth $(i)$ and drop $(j)$. The Poisson model is 165 often appropriate for modelling biological count data. Each effective abundance is the product of the expected abundance $\left(K_{i, j}\right)$ for that tributary mouth $(i)$ and drop $(j)$ given that the tributary is occupied and the probability that the tributary mouth is occupied (i.e., $z_{i}$ ):

$$
\gamma_{i, j}=z_{i} \times \Lambda_{i, j}
$$

To allow for greater differences in true abundance (i.e., $N_{i, j}$ ) among occupied tributary mouths

overdispersion, or variability greater than expected by the Poisson model:

$$
\log \left(\Lambda_{i, j}\right)=\alpha+e_{i, j}
$$

171 with $\log$ of expected local abundance $(\alpha)$, and added variability $\left(e_{i, j}\right)$ by tributary river mouth $(i)$

172 and drop $(j)$ distributed according to a normal distribution with mean zero and variance $\sigma^{2}$. An

173 estimate of $\sigma^{2}$ close to zero suggests minimal overdispersion. Accounting for variability is

174 important because abundance of larval lamprey varies at multiple spatial scales (Torgersen and

175 Close 2004; Stone and Barndt 2005). Abundance could vary temporally (i.e., sampling occurred

176 on different calendar days and in different years) or spatially as a result of factors at the tributary

177 level (i.e., number of dams to pass) and drop level (i.e., presence of appropriate sediment for

178 burrowing). For the third level, each count $\left(y_{i, j}\right)$ from a tributary $(i)$ and drop $(j)$ was a function

179 of the true abundance $\left(N_{i, j}\right)$ and capture probability $(p)$ :

$$
y_{i, j} \sim \operatorname{Binomal}\left(N_{i, j}, p\right)
$$

180 This level allows for non-100\% detection associated with the sampling process (i.e., it accounts

181 for the fact that some individuals within the perimeter of the electrofisher will not be collected

182 during the drop; Kéry and Schaub 2012). Usually, repeated sampling in the same location (i.e.,

183 multiple drops at the same spot) is completed to estimate capture probability and it is assumed 
184 that $N_{i, j}$ does not change between the repeated surveys. However, larval lamprey exhibit very 185 patchy distributions even at small spatial scales (Torgersen and Close 2004) and because our 186 collection and identification methods required that larvae be removed from sediments, it was not 187 possible to insure $N_{i, j}$ remained constant over multiple drops even within a quadrat. Thus, we 188 estimated capture probability $(p)$ using data from the experimental approach described above:

$$
C_{i} \sim \operatorname{Binomial}\left(A_{i}, p\right)
$$

All models were evaluated by Bayesian analysis methods using OpenBUGs software (Spiegelhalter et al. 2010). All priors were selected to be uninformative: for each capture probability experiment logistic regression model, the intercept and any slope values were each estimated from a normal distribution with a mean of zero and a variance of 1000; priors for Nmixture models are listed in Table 3. Capture probability evaluations included two initial chains run for 20000 iterations, with 10000 iterations removed as burn-in and the remaining 10000 used to produce posterior distributions. Both N-mixture models (i.e., one for Pacific lamprey 196 and one for Lampetra spp.) were also run with two initial chains, but for 100000 iterations with 19750000 iterations removed as burn-in, and the remaining 50000 iterations saved to produce 198 posterior distributions for all examined parameters. We report the median of the posterior 199 distribution as a measure of central tendency (i.e., as the expected value) and $2.5 \%$ and $97.5 \%$ 200 values in the posterior distribution as 95\% credible intervals to illustrate precision. We assessed 201 that convergence had occurred and that parameters had reached stable distributions by visually 202 examining history and density plots (Spiegelhalter et al. 2010; Kéry 2010).

To assess larval production in tributary river mouths, we produced density and abundance

204 estimates. We estimated the densities (i.e., larvae $\cdot \mathrm{m}^{-2}$ ) of larval Pacific lamprey and Lampetra $205 s p p$. in each electrofishing drop as $N_{i, j}$ divided by the area sampled by one drop (i.e., $0.42 \mathrm{~m}^{2}$ ). 
206 To estimate the average density in each tributary river mouth, we divided the calculated mean of

207 all $N_{i, j}$ in that mouth by the area of a drop. To estimate total abundance in each tributary river

208 mouth, we multiplied the estimated average density for that tributary river mouth by an estimate

209 of total area for that mouth. Total area for each tributary river mouth was the product of the

210 number of quadrats in the mouth and the total area of one quadrat (i.e., $900 \mathrm{~m}^{2}$ ).

\section{Spatial distribution}

We mapped spatial distribution and evaluated spatial overlap for Pacific lamprey and

213 Lampetra spp. in the Wind and Klickitat river mouths. We examined these two river mouths

214 because they were extensively sampled (Table 1; Fig. 2) and had both Pacific lamprey and

215 Lampetra spp. We mapped spatial distribution by plotting the average density (i.e., larvae $\cdot \mathrm{m}^{-2}$ )

216 for each sampled quadrat (all years combined) using ArcMap 9.3 (Environmental Systems

217 Institute, Redlands, California). Similar to other studies (Worischka et al. 2012; Wuenschel et al.

218 2012), we evaluated spatial overlap using Schoener's index of proportion similarity $(O)$ for the

219 Wind and Klickitat river mouths separately (Schoener 1970):

$$
O=1-0.5 \times\left(\sum_{j}^{\text {quad }}\left|p_{x, j}-p_{y, j}\right|\right.
$$

220 Where $p_{x, j}$ and $p_{y, j}$ were the average proportions of Pacific lamprey and Lampetra spp.

221 collected in each quadrat. Schoener's index values greater or equal to 0.6 are generally

222 considered to indicate biologically significant resource overlap (Wuenschel et al. 2012).

224 Results

We conducted 23 trials to estimate larval lamprey capture probability using the deepwater 226 electrofisher (Table 2). Of the 170 Pacific lamprey seeded into chambers, 112 were captured by 
227 electrofishing and 47 were found by manually sorting sediment following the experiment; thus,

22811 (of the 170) larvae were assumed to have escaped or be consumed by predators and were 229 removed from analysis of capture probability. The capture probability model with the lowest 230 AIC score did not include either measured covariate, although AIC scores for all models were 231 relatively similar, suggesting some support for all models, especially the two top models since 232 the $\triangle \mathrm{AIC}$ for those were less than 2.0 (Table 2; Burnham and Anderson 2002). The full model, 233 including a term for both length and density class had the highest $\Delta \mathrm{AIC}$ score (i.e., lowest ranked 234 model). For the full model, 95\% credible intervals on coefficients for both length class and 235 density class overlapped zero. Although a minimal decrease in capture probability was observed 236 with higher density and larger size, our results suggest no substantial relationship (Table 2).

237 Including no covariates, capture probability $(p)$ was estimated to be $0.70(95 \%: 0.63-0.77)$. We conducted 813 electrofishing drops in tributary river mouths, sampling $341 \mathrm{~m}^{2}$ of 239 sediment. In total, 145 collected larvae were identified as Pacific lamprey and 115 larvae were 240 identified as Lampetra spp. In addition, 18 small larval lamprey (typically $<20 \mathrm{~mm}$ TL) were 241 observed to be lost through the mesh in the collection basket and thus were not identified. These 242 individuals were not included in analyses. Larval Pacific lamprey ranged in size from $18 \mathrm{~mm}$ to $243136 \mathrm{~mm}$ TL with $87 \%$ between 20 and $80 \mathrm{~mm}$ TL and a peak of $38 \%$ between 30 and $40 \mathrm{~mm}$ TL 244 (Fig. 3). Lampetra spp. ranged in size from 14 to $152 \mathrm{~mm}$ TL with $85 \%$ between 20 and $90 \mathrm{~mm}$ 245 TL and no distinct peak observed (Fig. 3).

Pacific lamprey were found in tributary river mouths of Bonneville, The Dalles, and John 247 Day reservoirs (Table 4; Fig. 1). Pacific lamprey were detected in 7 of 10 sampled tributary 248 river mouths and the probability of occupancy for a tributary river mouth was estimated to be 249 0.70 (95\%: $0.41-0.93)$. For river mouths in which no Pacific lamprey were collected, estimated 
250 probabilities of occupancy were 0.11. Larval Pacific lamprey were collected at depths ranging 251 from 0.6 to $8.5 \mathrm{~m}$. Estimated larval densities varied both within and among tributary river 252 mouths and the $95 \%$ credible interval on variance $\left(\sigma^{2}\right)$ did not include zero, indicating 253 heterogeneity (Table 3). Estimated average densities in occupied river mouths ranged from $2540.18 \cdot \mathrm{m}^{-2}$ to $1.72 \cdot \mathrm{m}^{-2}$; however, in five of seven occupied river mouths, estimated densities were $2550.18 \cdot \mathrm{m}^{-2}$ to $0.26 \cdot \mathrm{m}^{-2}$ (Table 4$)$. The maximum estimated density from a drop was $33.33(95 \%$ : $25623.81-47.62)$ larvae $\cdot \mathrm{m}^{-2}$. For tributary river mouths determined to be occupied by Pacific 257 lamprey, larval abundance ranged from 11530 (95\%: 7689 - 23 070) in the John Day River 258 mouth to 556600 (95\%: 448700 - 651 600) in the Klickitat River mouth (Table 4).

Lampetra spp. were collected from all five sampled tributary river mouths to Bonneville Reservoir and none upstream of The Dalles Dam (Table 4; Fig. 1). The mean probability of tributary river mouth occupancy was $0.51(95 \%: 0.24-0.78)$. The model suggested very small

262 probabilities of potential occupancy for tributary river mouths in which no Lampetra spp. were 263 collected; the probability was lower for the Deschutes River $(<0.01)$ which was sampled by 72 264 drops, than for all other tributaries in which no individuals were collected (0.03) since those were 265 sampled by 34 drops (Table 4). Larval Lampetra spp. were collected at depths of 0.3 to $8.5 \mathrm{~m}$. 266 Similar to Pacific lamprey, the $95 \%$ credible interval on variance $\left(\sigma^{2}\right)$ was substantially above 267 zero, suggesting higher variability in drop counts than expected by the Poisson model (Table 3 ). 268 Average estimated density in an occupied tributary river mouth was $0.24-1.72 \cdot \mathrm{m}^{-2}$ (Table 4). 269 Similar to Pacific lamprey, maximum average density was $1.72 \cdot \mathrm{m}^{-2}$, but in most river mouths 270 average densities were lower (Table 4). For both lamprey species, average densities in tributary 271 river mouths were most commonly $0.2-0.3 \cdot \mathrm{m}^{-2}$ (Table 4 ). The maximum estimated density of 272 Lampetra spp. observed from a drop was $38.10(95 \%: 28.57-54.76)$ larvae $\cdot \mathrm{m}^{-2}$. For tributary 
273 river mouths known to be occupied, abundance of Lampetra spp. ranged from 95030 (95\%: 67

$274880-131200)$ in the mouth of the Klickitat River to $544800(95 \%: 477300-634900)$ in the

275 mouth of the Wind River (Table 4).

276 Pacific lamprey and Lampetra spp. overlapped spatially, although the highest densities

277 and abundances were found in different tributary river mouths (Table 4). Density and abundance

278 were highest for Pacific lamprey in the Klickitat River mouth, whereas they were highest for

279 Lampetra spp. in the Wind River mouth, although both lampreys were found in both systems

280 (Table 4). A total of 83 of the 338 drops completed in the Klickitat and Wind river mouths

281 combined contained at least one lamprey and 26 of those 83 occupied drops (31\%) contained at

282 least one individual of both species. Thus, nearly a third of the occupied drops in the Klickitat

283 and Wind river mouths contained both species of lamprey, suggesting spatial overlap, at least at

284 the scale of a drop. For both lampreys, quadrats with high densities appeared to correspond to

285 areas in the river mouth that were more directly impacted by discharge from the tributary river

286 (Fig. 4). While distribution overlapped in both tributary river mouths, areas of highest density

287 differed somewhat (Fig. 4). Schoener's index of proportion similarity $(O)$ was 0.41 in the

288 Klickitat River mouth and 0.58 in the Wind River mouth indicating similarity in spatial resource 289 use, but suggesting that overlap may not be biologically significant (i.e., both were $<0.6$ ).

291 Discussion

We produced the first estimates of density and abundance of larval Pacific lamprey and

293 Lampetra spp. in tributary river mouths in an impounded river. In most occupied river mouths,

294 average densities were 0.2 to $0.3 \cdot \mathrm{m}^{-2}$, although in some river mouths average densities were

295 much higher (up to $1.72 \cdot \mathrm{m}^{-2}$ ) and there was considerable variability. Average and maximum 
296 larval densities in river mouths appear generally lower than those within streams (Ojutkangas et 297 al. 1995; Torgersen and Close 2004; Stone and Barndt 2005), which may be a function of 298 distance from spawning areas, habitat quantity or quality, or sampling differences. Todd and 299 Kelso (1993) observed larval Geotria autralis in New Zealand freshwater streams from headwaters to sea, but noted that a higher percentage were collected from small tributaries $(<10$ m wide) as compared to larger downstream channels ( $>20 \mathrm{~m}$ wide). Some small larvae (i.e., $<20$ mm TL) escaped our collection basket, which would bias our density and abundance estimates low. Despite potential differences in density in different freshwater environments, we collected larval lampreys at depths up to $8.5 \mathrm{~m}$ and our estimates illustrate considerable rearing in deepwater tributary river mouths upstream of dams in the Columbia River Basin, suggesting the potential importance of these areas to population status and conservation. mouth was occupied, if no larvae were collected. This is particularly important for Pacific lamprey, since status is currently more commonly assessed by distribution, rather than by abundance (Jolley et al. 2012; Dunham et al. 2013; Reid and Goodman 2015). Our results 311 suggest that the probability of occupancy in river mouths in which no Pacific lamprey were 312 detected would be fairly low at 0.11 with 34 drops. For Lampetra spp., the probability of 313 occupancy where no larvae were collected was even lower at 0.03 with 34 drops. Although both 314 Pacific lamprey and Lampetra spp. have been found upstream of McNary Dam (Moser and 315 Close 2003; Grote et al. 2014; Meeuwig et al. 2005), we did not find any Pacific lamprey in river mouths in McNary Reservoir and we collected no Lampetra spp. upstream of The Dalles Dam.

317 Reduced occupancy in upstream areas may partially be a function of impeded adult migration at 318 dams for the anadromous Pacific lamprey and western river lamprey (Moser et al. 2002). 
319 Western river lamprey can be common in estuaries (Vladykov and Follett 1958; Weitkamp et al.

320 2015), but records from upstream of Bonneville Dam are scarce (Vladykov and Follett 1958;

321 Jolley et al. 2016). Western brook lamprey are not highly migratory (Moser et al. 2015a) and

322 there may be multiple highly localized riverine populations in the Columbia River Basin that 323 may not use tributary river mouths (USFWS unpublished data).

Although considerable spatial overlap occurred, there were differences in distribution of 325 Pacific lamprey and Lampetra spp. within and among occupied tributary river mouths. Adult 326 spawning site selection may affect large-scale larval distribution; thus, variation among river 327 mouths may result from differences in spawning habitat preferences and migration patterns 328 (especially anadromous vs. resident). Generally, western brook lamprey produce smaller redds 329 in areas characterized by shallower depths, slower water velocities, and smaller substrates, as 330 compared to Pacific lamprey, which are much larger in size as adults (Stone 2006; Gunckel et al. 331 2009; Hayes et al. 2013). Spatial distribution patterns could also result from dissimilarities in 332 larval habitat preferences as suggested by Taverny et al. (2012) for Petromyzon and Lampetra; 333 although, various species of larval lamprey appear to prefer fine sand for burrowing (Stone and 334 Barndt 2005; Sugiyama and Goto 2002; Smith et al. 2011; Ferreira et al. 2013). We observed 335 spatial overlap in the Klickitat and Wind river mouths; however, average densities were different 336 and Schoener's index values were not greater than 0.6 (although 0.58 in the Wind River) 337 potentially indicating that the spatial resource overlap was not biologically significant. Perhaps, 338 habitat preferences for larvae affect distribution at a small scale (such as in a drop) and adult 339 behaviors affect distribution at a larger scale (such as in a tributary unit). correctly account for the capture probability of an individual (Kéry et al. 2009). Often, capture 
342 probability is estimated in an N-mixture model by the pattern of counts collected by multiple 343 surveys at multiple sites (Kéry and Schaub 2012); however, our sampling methods and larval 344 lamprey biology made it impossible for us to ensure that we could sample the same individuals 345 during multiple surveys in the wild (i.e., it was impossible to assume closure). As a result, we 346 estimated capture probability experimentally. Closure may be impossible in some studies, 347 especially when the target species must be captured (or handled) to confidentially identify or is 348 highly mobile; thus, estimating capture probability experimentally can make abundance 349 estimation by N-mixture model analysis possible. We estimated capture probability to be 0.70 350 (95\% credible interval: $0.63-0.77)$, which is only slightly lower than the $0.75(95 \%$ confidence 351 interval: $0.63-0.93)$ estimated by Bergstedt and Genovese (1994) using the same electrofishing 352 method to collect sea lamprey. Small differences in capture probability between the two studies 353 may be a result of differences between species, estimation methods, or experimental settings.

354 Our estimates were made in relatively cold, low conductivity water, which may lower the 355 response rate of larval lampreys to electric stimuli (Bowen et al. 2003). However, expected 356 values were generally similar and intervals overlapped among the two studies, corroborating 357 results from both studies. Deepwater electrofishing capture probability for larval lampreys 358 appears high, which is beneficial since higher capture probability can result in increased 359 accuracy and precision of abundance estimates from N-mixture models (Veech et al. 2016). 360 Recent experimental work suggests that larval Pacific lamprey burrow close to the sediment 361 surface (Liedtke et al. 2015); thus, it is likely that most, if not all, burrowed individuals are 362 available for capture by deepwater electrofishing. If capture probability is substantially impacted by environmental or individual covariates, 364 estimates of length distribution and density could be biased (Breton et al. 2013; Veech et al. 
365 2016). In our experiments, the selected capture probability model did not include either larval 366 length or density as a covariate. However, Bergstedt and Genovese (1994) modeled length as a 367 continuous parameter and found that capture probability decreased as size increased for larval 368 sea lamprey and our experimental results illustrated some support for a capture probability model 369 that included larval length. Our selected model may not have included larval length due to small 370 sample sizes or because we recorded length as a categorical variable instead of a continuous 371 variable. Similar to other types of electrofishing (Millar et al. 2016), capture probability of the

372 deepwater electrofisher could be impacted by local environmental factors such as water

373 conductivity, temperature, and depth, as well as sediment type. Research to examine deepwater 374 electrofishing capture probability as a function of local environmental parameters would be 375 valuable. Incorporating environmentally-based estimates of capture probability would improve 376 estimates of density and abundance. Our research suggests that evaluating catch data from a deepwater electrofisher using an 378 N-mixture model is an effective method for estimating abundance of larval lampreys. Data for 379 N-mixture models are counts (which are often sparse) from multiple sites (Royle 2004). These 380 models assume that abundance at each site is an independent random variable from a 381 distribution, such as the Poisson distribution. These models incorporate capture probability, so 382 counts are scaled up to estimate abundance (Kéry and Schaub 2012). N-mixture models 383 generally produce accurate and precise estimates of abundance when capture probability is above 3840.5 (Veech et al. 2016), as it appears to be for larval lampreys collected by a deepwater 385 electrofisher. Other techniques to estimate abundance, such as mark-recapture and distance 386 sampling (Williams et al. 2002), are logistically difficult to implement for larval lampreys in 387 large, open systems such as tributary river mouths; in contrast, collecting count data by 
388 deepwater electrofishing is feasible (Jolley et al. 2012). Assessing periodic trends or how

389 environmental factors may impact occupancy and density could be evaluated with only minimal

390 changes to the model structure (Wenger and Freeman 2008; Kéry et al. 2009), although such

391 analyses would require additional sampling effort.

392

Our results quantify considerable use of upstream tributary river mouths for rearing, but

the extent to which these areas currently contribute to the Pacific lamprey population across its range is still unclear. Once upstream of impediments in the Columbia River Basin, adult Pacific lamprey can migrate up to hundreds of river kilometres before spawning (McIlraith et al. 2015). However, research is still required to assess the contribution of larvae reared upstream of impediments because mortality rates may be higher there, particularly during emigration periods, than for individuals spawned downstream of dams. We also do not know how larval growth and survival rates in these deeper-water tributary river mouths compare to those in wadeable streams;

400 however, recent work in the Great Lakes suggests that larval sea lamprey exhibit slower growth, 401 but slightly higher survival, in lentic areas as opposed to streams (Johnson et al. In Press). Since 402 Pacific lamprey and western river lamprey are anadromous, connectivity within rivers is vital.

403 Our study illustrated the value of using count data from deepwater electrofishing analyzed by N404 mixture models to estimate density and abundance of larval lampreys and provided abundance 405 estimates for tributary river mouths upstream of dams. In combination with our results, 406 additional studies similar to Keefer et al. (2013) to evaluate downstream passage efficiency and 407 passage limitations at dams in the Columbia River would help assess the actual and potential 408 contribution of larvae reared in upstream tributary river mouths to the conservation of Pacific 409 lamprey across the species range. 


\section{Acknowledgements}

Greg Silver is appreciated for technical expertise with GRTS and GIS, extensive field efforts, and comments on a previous draft of this manuscript. Steven Haeseker, Timothy

Whitesel, Howard Schaller, Joseph Skalicky, and Christina Wang contributed to funding support, study design, and manuscript review. David Hines produced the maps. Many people from the U.S. Fish and Wildlife Service provided sampling and administrative support. Funding was provided by the U.S. Army Corps of Engineers and the U.S. Fish and Wildlife Service/Columbia River Fish and Wildlife Conservation Office. References to trade names do not imply endorsement by the U.S. Government. The findings and conclusions in this manuscript are those of the authors and do not necessarily represent the views of the U.S. Fish and Wildlife Service.

\section{References}

Aronsuu, K., and Virkkala, P. 2014. Substrate selection by subyearling European river lampreys (Lampetra fluviatilis) and older larvae (Lampetra spp). Ecol. Freshw. Fish 23(4):644-65.

Beamish, R.J. 1980. Adult biology of river lamprey (Lampetra ayresi) and the Pacific lamprey (Lampetra tridentata) from the Pacific Coast of Canada. Can. J. Fish. Aquat. Sci. 37(11):1906-1923.

Bergstedt, R.A., and Genovese, J.H. 1994. New technique for sampling sea lamprey larvae in deepwater habitats. N. Am. J. Fish. Manage. 14(2):449-452.

Bowen, A.K, Weisser, J.W., Bergstedt, R.A., Famoye, F. 2003. Response of larval sea lampreys (Petromyzon marinus) to pulsed DC electrical stimuli in laboratory experiments. J. Great Lakes Res. 29 (Suppl. 1):174-182. 
433 Breton, A., Hawkins, J.A., and Winkelman, D.L. 2013. Correcting length-frequency distributions 434 for imperfect detection. N. Am. J. Fish. Manage. 33(6):1156-1165.

435 436

437 438 439 440 441

442 443

444 445 446 447 448 449 450 451 452 453 454 455

Burnham, K.P., and Anderson, D.R. 2002. Model selection and multimodal inference: a practical information-theoretic approach, $2^{\text {nd }}$ Edition. Springer Science, New York, NY. 488 pp.

Close, D.A., Fitzpatrick, M.S., and Li, H.W. 2002. The ecological and cultural importance of a species at risk of extinction, Pacific lamprey. Fisheries 27(7):19-25.

Dawson, H.A., Quintella, B.R., Almeida, P.R., Treble, A.J., and Jolley, J.C. 2015. The ecology of larval and metamorphosing lampreys. In Lampreys: biology, conservation, and control. Edited by M.F. Docker. Springer Science, New York. pp. 75-137.

Docker, M.F. 2009. A review of the evolution of nonparasitism in lampreys and an update of the paired species concept. In Biology, management, and conservation of lampreys in North America. Edited by L.R. Brown, S.D. Chase, M.G. Mesa, R.J. Beamish, and P.B. Moyle. American Fisheries Society Symposium, 72, Bethesda, MD. pp. 71-114.

Docker, M.F., Silver, G.S., Jolley, J.C., and Spice, E.K. 2016. Simple genetic assay distinguishes lamprey Genera Entosphenus and Lampetra: comparison with existing genetic and morphological identification methods. N. Am. J. Fish. Manage. 36(4):780-787.

Dunham, J.B., Chelgren, N.D., Heck, M.P., and Clark, S.M. 2013. Comparison of electrofishing techniques to detect larval lamprey in wadeable streams in the Pacific Northwest. N. Am. J. Fish. Manage. 33(6):1149-1155.

Ferreira, A.F., Quintella, B.R., Maia, C., Mateus, C.S., Alexandre, C.M, Capinha, C., and Almeida, P.R. 2013. Influences of macrohabitat preferences on the distribution of European brook and river lampreys: implications for conservation and management. Biol. Conserv. 159:175-186. 
Fodale, M.F., Bronte, C.R., Bergstedt, R.A., Cuddy, D.W., and Adams, J.V. 2003. Classification of lentic habitat for sea lamprey (Petromyzon marinus) larvae using a remote seabed classification device. J. Great Lakes Res. 29 (Suppl. 1):190-203.

Goodman, D.H., Reid, S.B., Docker, M.F., Haas, G.R., and Kinziger, A.P. 2008. Mitochondrial DNA evidence for high levels of gene flow among populations of a widely distributed anadromous lamprey Entosphenus tridentatus (Petromyzontidae). J. Fish Biol. 72(2):400417.

Grote, A.B., Nelson. M.C., Yonce, C., Johnson, A., Sulak, D.J., and Nelle, R.D. 2014. Passage of radio-tagged adult Pacific lamprey at Yakima River diversion dams. 2013 Annual Report. U.S. Fish and Wildlife Service, Leavenworth, WA. 49 pp.

Gunckel, S.L., Jones, K.K., and Jacobs, S.E. 2009. Spawning distribution and habitat use of adult Pacific and western brook lampreys in Smith River, Oregon. In Biology, management, and conservation of lampreys in North America. Edited by L.R. Brown, S.D. Chase, M.G. Mesa, R.J. Beamish, and P.B. Moyle. American Fisheries Society Symposium, 72, Bethesda, MD. pp. 173-189.

Hayes, M.C., Hays R., Rubin, S.P., Chase, D.M., Hallock, M., Cook-Tabor, C., Luzier, C.W., and Moser, M.L. 2013. Distribution of Pacific lamprey Entosphenus tridentatus in watersheds of Puget Sound based on smolt monitoring data. Northwest Sci. 87(2):95-105.

Johnson, N.S., Brenden, T.O., Swink, W.D., and Lipps, M.A. In Press. Survival and metamorphosis of larval sea lamprey (Petromyzon marinus) residing in Lakes Michigan and Huron near river mouths. J. Great Lakes Res. Available online (10/4/2016): http://www.sciencedirect.com/science/article/pii/S0380133016301745. 
478 Jolley, J.C., Kovalchuk, G., and Docker, M.F. 2016. River lamprey (Lampetra ayresii)

479 outmigrant upstream of The John Day Dam in the Mid-Columbia River. Northwest Nat. $480 \quad 97: 47-52$.

481 Jolley, J.C., Silver, G.S., and Whitesel, T.A. 2012. Occupancy and detection of larval Pacific 482 483

484 485 486 487 488 489 490 491

Kéry, M. 2010. Introduction to WinBUGS for Ecologists: A Bayesian approach to regression, lamprey and Lampetra spp. in a large river: the lower Willamette River. Trans. Am. Fish. Soc. 141(2):305-312.

Keefer, M.L., Boggs, C., Peery, C.A., and Caudill, C. 2013. Factors affecting dam passage and upstream distribution of adult Pacific lamprey in the interior Columbia River basin. Ecol. Freshw. Fish 22(1):1-10.

Lee, D.S., and Weise, J.D. 1989. Habitat selection of lentic larval lampreys: Preliminary analysis based on research with a manned submersible. J. Great Lakes Res. 15:156-163. ANOVA, mixed models and related analyses. Academic Press, Burlington, MA. 302 pp.

Kéry, M., Dorazio, R.M., Soldaat, L., van Strien, A., Zuiderwijk, A., and Royle, J.A. 2009. Trend estimation in populations with imperfect detection. J. Appl. Ecol. 46(6):11631172.

Kéry, M., and Schaub, M. 2012. Bayesian population analysis using WinBUGS: a hierarchical perspective. Academic Press, Waltham, MA. 535 pp. River hydropower system operations - effects of dewatering on larval lamprey movements and survival. U.S. Geological Survey, Cook, WA. 
Maitland, P.S., Renaud, C.R., Quintella, B.R., Close, D.A., and Docker, M.F. 2015. Conservation of native lampreys. In Lampreys: biology, conservation, and control. Edited by M.F. Docker. Springer Science, New York. pp. 375-428.

McIlraith, B.J., Caudill, C.C., Kennedy, B.P., Peery, C.A., Keefer, M.L. 2015. Seasonal migration behaviors and distribution of adult Pacific Lampreys in unimpounded reaches of the Snake River Basin. N. Am. Fish. Manage. 35(1):123-143.

Meeuwig, M.H., Bayer, J.M., and Seelye, J.G. 2005. Effects of temperature on survival and development of early life stage Pacific and western brook lampreys. Trans. Am. Fish. Soc. 134(1):19-27.

Millar, C.P., Fryer, R.J., Millidine, K.J., and Malcolm, I.A. 2016. Modelling capture probability of Atlantic salmon (Salmo salar) from a diverse national electrofishing dataset: implications for the estimation of abundance. Fish. Res. 177:1-12.

Moser, M.L., Almeida, P.R., Kemp, P.S., and Sorensen, P.W. 2015a. Lamprey spawning migration. In Lampreys: biology, conservation, and control. Edited by M.F. Docker. Springer Science, New York. pp. 215-263.

Moser, M.L., Butzerin, J.M., and Dey, D.B. 2007. Capture and collection of lampreys: the state of the science. Rev. Fish Biol. Fisher. 17(1):45-56.

Moser, M.L., and Close, D.A. 2003. Assessing Pacific lamprey status in the Columbia River basin. Northwest Sci. 77(2):116-125.

Moser, M.L., Jackson, A.D., Lucas, M.C., and Mueller, R.P. 2015b. Behavior and potential threats to survival of migrating lamprey ammocoetes and macrophthalmia. Rev. Fish Biol. Fisher. 25(1):103-116. 
521 Moser, M.L., Ocker, P.A., Stuehrenberg, L.C., and Bjornn, T.C. 2002. Passage efficiency of 522 adult Pacific lampreys at hydropower dams on the Lower Columbia River, USA. Trans. $523 \quad$ Am. Fish. Soc. 131(5):956-965.

524 Noble, M., Duncan, P., Perry, D., Prosper, K., Rose, D., Schnierer, S., Tipa, G., Williams, E., 525 Woods, R., and Pittock J. 2016. Culturally significant fisheries: keystones for management of freshwater social-ecological systems. Ecol. Soc. 21(2):22.

Ojutkangas, E., Aronen, K., and Laukkanen, E. 1995. Distribution and abundance of river lamprey (Lampetra fluviatilis) ammocoetes in the regulated river Perhonjoki. Regul. River. 10(2-4):239-245.

Renaud, C.B. 1997. Conservation status of Northern Hemisphere lampreys (Petromyzontidae). J. Appl. Ichthyol. 13(3):143-148.

Reid, S.B., and Goodman, D.H. 2015. Detectability of Pacific lamprey occupancy in western drainages: implications for distribution surveys. Trans. Am. Fish. Soc. 144(2):315-322.

Riemer, S.D., Wright, B.E., and Brown, R.F. 2011. Food habits of steller seas lions (Eumetopias jubatus) off Oregon and northern California, 1986-2007. Fish. Bull. 109(4):369-381.

Royle, J.A. 2004. N-mixture models for estimating population size from spatially replicated counts. Biometrics 60(1):108-115.

Ruiz-Campos, G., and Gonzalez-Guzman, S. 1996. First freshwater record of Pacific lamprey, Lamptera tridentata, from Baja California, Mexico. Calif. Fish Game 82:144-146.

540 Schoener, T.W. 1970. Nonsynchronous spatial overlap of lizards in patchy habitats. Ecology 51(3):408-418.

542 Slade, J.W., Adams, J.V., Christie, G.C., Cuddy, D.W., Fodale, M.F., Heinrich, J.W., Quinlan,

543 H.R., Weise, J.G., Weisser, J.W., Young, R.J. 2003. Techniques and methods for 
estimating abundance of larval and metamorphosed sea lampreys in Great Lake tributaries, 1995 to 2001. J. Great Lakes Res. 29 (Suppl. 1):137-151.

Smith, D.M., Welsh, S.A., and Turk, P.J. 2011. Selection and preferences of benthic habitat by small and large ammocoetes of the least brook lamprey (Lampetra aepyptera). Environ. Biol. Fishes 91(4):421-428.

Spice, E.K., Goodman, D.H., Reid, S.B., and Docker, M.F. 2012. Neither philopatic nor panmictic: microsatellite and mtDNA evidence suggests lack of natal homing but limited dispersal in Pacific lamprey. Mol. Ecol. 21(12):2916-2930.

Spice, E.K., Whitesel, T.A., McFarlane, C.T., and Docker, M.F. 2011. Characterization of 12 microsatellite loci for the Pacific lamprey, Entosphenus tridentatus (Petromyzontidae), and cross-amplification in five other lamprey species. Genet. Mol. Res. 10(4):3246-3250.

Spiegelhalter, D., Thomas, A., Best, N., and Lunn, D. 2010. OpenBUGS user manual, version 3.1.2. MRC Biostatistics Unit, Cambridge, MA.

Stevens, D.L., and Olsen, A.R. 2004. Spatially balanced sampling of natural resources. J. Am. Stat. Assoc. 99(465):262-278.

Stone, J., and Barndt, S. 2005. Spatial distribution and habitat use of Pacific lamprey (Lampetra tridentata) ammocoetes in a western Washington stream. J. Fresh. Ecol. 20(1):171-185.

Stone, J. 2006. Observations on nest characteristics, spawning habitat, and spawning behavior of Pacific and western brook lamprey in a Washington stream. Northwestern Nat. 87(3):225-232.

Sugiyama, H., and Goto, A. 2002. Habitat selection by larvae of a fluvial lamprey, Lethenteron reissneri, in a small stream and an experimental aquarium. Ichthyol. Res. 49(1):62-68. 
566 567

Taverny, C., Lassalle, G., Ortusi, I., Roqueplo, C., Lepage, M., and Lambert, P. 2012. From shallow to deep waters: habitats used by larval lampreys (genus Petromyzon and Lampetra) over a western European basin. Ecol. Freshw. Fish 21(1):87-99.

Todd, P.R., and Kelso, J.R.M. 1993. Distribution, growth, and transformation timing of larval Geotria australis in New Zealand. Ecol. Freshw. Fish 2(3):99-107.

Torgersen, C.E., and Close, D.A. 2004. Influence of habitat heterogeneity on the distribution of larval Pacific lamprey (Lampetra tridentate) at two spatial scales. Freshw. Biol. 49(5):614-630.

Veech, J.A., Ott, J.R., and Troy, J.R. 2016. Intrinsic heterogeneity in detection probability and its effect on N-mixture models. Methods. Ecol. Evol. 7(9):1019-1028.

Vladykov, V.D., and Follett, W.I. 1958. Redescription of Lampetra ayresii (Günther) of western North America, a species of lamprey (Petromyzontidae) distinct from Lampetra fluviatilis (Linnaeus) of Europe. J. Fish. Res. Board Can. 15(1):47-77.

Wang, C., and Schaller, H. 2015. Conserving Pacific lamprey through collaborative efforts. Fisheries 40(2):72-79.

Weitkamp, L.A., Hinton, S.A., and Bentley, P.J. 2015. Seasonal abundance, size, and host selection of western river (Lampetra ayresii) and Pacific (Entosphenus tridentatus) lampreys in the Columbia River estuary. Fish. Bull. 113(2):213-226.

Wenger, S.J., and Freeman, M.C. 2008. Estimating species occurrence, abundance, and detection probability using zero-inflated distributions. Ecology 89(10):2953-2959.

Williams, B.K, Nichols, J.D., and Conroy, M.J. 2002. Analysis and management of animal populations: modeling, estimation, and decision making. Academic Press, Boston, MA. $817 \mathrm{pp}$. 
589 Worischka, S., Koebsch, C., Hellmann, C., and Winkelmann, C. 2012. Habitat overlap between 590 predatory benthic fish and their invertebrate prey in streams: the relative influence of spatial and temporal factors on predation risk. Freshw. Biol. 57(11):2247-2261.

592 Wuenschel, M.J., Able, K.W., Vasslides, J.M., and Byrne, D.M. 2012. Habitat and diet overlap 593 of 4 piscivorous fishes: variation on the inner continental shelf off New Jersey. Fish. Bull. 111(4):352-369.

595 Wydoski, R.S., and Whitney, R.R. 2003. Inland fishes of Washington, $2^{\text {nd }}$ edition. American 596 597 Fisheries Society and University of Washington Press, Bethesda, Maryland, and Seattle, Washington.

598 Yamazaki, Y., Fukutomi, N., Oda, N., Shibukawa, K., Niimura, Y., and Iwata, A. 2005. 599 Occurrence of larval Pacific lamprey Entosphenus tridentatus from Japan, detected by 600 random amplified polymorphic DNA (RAPD) analysis. Ichthyol. Res. 52(3):297-301. 
Table 1. Stream order at the mouth (at the 1:100 000 scale), river kilometre ("Rkm") for the Columbia River, and estimated total area (in $\mathrm{m}^{2}$ ) of each mouth, as well as the number of quadrats sampled (i.e., number of drops completed) during each year (labelled by the year) for each tributary river mouth in the Columbia River basin upstream of Bonneville Dam sampled by deepwater electrofishing.

\begin{tabular}{|c|c|c|c|c|c|c|c|c|c|}
\hline Reservoir & Tributary name & Stream order & Rkm & Area & 2011 & 2012 & 2013 & 2014 & 2015 \\
\hline \multirow[t]{5}{*}{ Bonneville } & Wind River & 5 & 249 & 317700 & 32 & 34 & 102 & & \\
\hline & Little White Salmon River & 4 & 262 & 346500 & & & 34 & & \\
\hline & White Salmon River & 5 & 269 & 380700 & & 34 & 34 & & \\
\hline & Hood River & 5 & 273 & 462600 & 34 & & 35 & & \\
\hline & Klickitat River & 5 & 290 & 323100 & 34 & 34 & 102 & & \\
\hline The Dalles & Deschutes River & 6 & 330 & 380700 & & 38 & 34 & & \\
\hline \multirow[t]{2}{*}{ John Day } & John Day River & 6 & 352 & 54900 & & & & 34 & \\
\hline & Umatilla River & 6 & 466 & 397800 & & & & 34 & \\
\hline \multirow[t]{2}{*}{ McNary } & Walla Walla River & 6 & 506 & 588600 & & & & & 34 \\
\hline & Yakima River & 7 & 539 & 432900 & & & & 23 & 11 \\
\hline
\end{tabular}

Note: Locations of all tributary river mouths are in Fig. 1. 
Table 2. Experiment information and model selection to estimate capture probability of larval Pacific lamprey using deepwater electrofishing: A) number of trials, average ambient water conductivity and temperature (with ranges), and expected proportions captured (with 95\% credible intervals) as estimated by the full model, by density in the chamber (i.e., five or 10 larvae) and total length class; and B) number of parameters (k) and Akaike's Information Criterion (AIC) results for all examined capture probability models ( $\triangle \mathrm{AIC}$ indicates the difference in AIC between the listed model and the model with the lowest AIC value).

\begin{tabular}{lccccc} 
A) & \multicolumn{7}{c}{} & & \\
\hline Length & Density & \# of & Ambient conductivity & Temperature $\left({ }^{\circ} \mathrm{C}\right)$ & Proportion \\
$(\mathrm{mm})$ & $\left(\mathrm{m}^{-2}\right)$ & trials & $\left(\mu \mathrm{S} \mathrm{cm}^{-1}\right)$ & & captured \\
\hline$<70$ & 12 & 6 & $34.3(32.3-37.7)$ & $7.5(7.2-7.6)$ & $0.77(0.63-0.87)$ \\
$<70$ & 24 & 5 & $34.9(34.3-35.6)$ & $8.7(8.6-8.8)$ & $0.74(0.62-0.84)$ \\
$>80$ & 12 & 6 & $33.4(33.1-34.3)$ & $10.0(9.9-10.2)$ & $0.69(0.53-0.82)$ \\
$>80$ & 24 & 6 & $34.5(33.1-36.1)$ & $10.9(10.8-11.1)$ & $0.66(0.54-0.76)$
\end{tabular}

B)

\begin{tabular}{llllll}
\hline Model & Estimated parameters & Mean of deviance & $\mathrm{k}$ & AIC & $\Delta$ AIC \\
\hline No covariates & $I$ & 72.25 & 1 & 74.25 & 0 \\
Length class & $I, b_{2}$ & 71.48 & 2 & 75.48 & 1.23 \\
Density class & $I, b_{1}$ & 73.11 & 2 & 77.11 & 2.86 \\
Full model & $I, b_{1}, b_{2}$ & 72.39 & 3 & 78.39 & 4.14 \\
\hline
\end{tabular}


Table 3. Prior distributions and posterior estimates (with $95 \%$ credible intervals) for the N-mixture models to estimate density and total abundance of larval Pacific lamprey and Lampetra spp. in tributary river mouths to the impounded portion of the Columbia River basin including the probability of occupancy $(\Omega), \log$ of expected local abundance $(\alpha)$, variance on local abundance as a function of differences in tributary river mouth and drop $\left(\sigma^{2}\right)$, and capture probability as estimated by an experimental approach $(p)$.

\begin{tabular}{cccc}
\hline Parameter & Prior Distribution & Pacific lamprey & Lampetra spp. \\
\hline$\Omega$ & Uniform $(0,1)$ & $0.70(0.41-0.93)$ & $0.51(0.24-0.78)$ \\
$\alpha$ & Normal $\left(0,10^{3}\right)$ & $-4.21(-5.48--3.42)$ & $-3.54(-4.56--2.80)$ \\
$\sigma^{2}$ & Uniform $(0,10)$ & $2.71(2.21-3.48)$ & $2.31(1.83-2.96)$ \\
$p$ & Uniform $(0,1)$ & & $0.70(0.63-0.77)$ \\
\hline
\end{tabular}


Table 4. Estimates of occupancy probability, density, and abundance of Pacific lamprey (upper panel) and Lampetra spp. (lower panel) in tributary river mouths to the Columbia River, Oregon and Washington, Bonneville Reservoir to McNary Reservoir.

\section{Pacific lamprey}

\begin{tabular}{lrrrrr}
\hline Tributary name & Occupancy probability & \# of larvae & \# of drops & Density $\left(\mathrm{m}^{-2}\right)$ & Abundance \\
\hline Wind River & 1 & 40 & 168 & $0.79(0.67-0.96)$ & $252100(211600-306200)$ \\
Little White Salmon River & 0.11 & 0 & 34 & $0.00(0.00-0.07)$ & $0(0-24260)$ \\
White Salmon River & 1 & 3 & 68 & $0.18(0.11-0.35)$ & $66650(39990-133300)$ \\
Hood River & 1 & 4 & 69 & $0.21(0.14-0.38)$ & $95780(63850-175600)$ \\
Klickitat River & 1 & 89 & 170 & $1.72(1.51-2.02)$ & $556600(488700-651600)$ \\
Deschutes River & 1 & 5 & 72 & $0.26(0.17-0.46)$ & $100700(62950-176300)$ \\
John Day River & 1 & 2 & 34 & $0.21(0.14-0.42)$ & $11530(7689-23070)$ \\
Umatilla River & 1 & 2 & 34 & $0.21(0.14-0.42)$ & $83570(55710-167100)$ \\
Walla Walla River & 0.11 & 0 & 34 & $0.00(0.00-0.07)$ & $0(0-41220)$ \\
Yakima River & 0.11 & 0 & 34 & $0.00(0.00-0.07)$ & $0(0-30320)$ \\
\hline
\end{tabular}


Table 4 Continued

\section{Lampetra spp.}

\begin{tabular}{|c|c|c|c|c|c|}
\hline Tributary name & Occupancy probability & \# of larvae & \# of drops & Density $\left(\mathrm{m}^{-2}\right)$ & Abundance \\
\hline Wind River & 1 & 89 & 168 & $1.72(1.50-2.00)$ & $544800(477300-634900)$ \\
\hline Little White Salmon River & 1 & 4 & 34 & $0.42(0.28-0.70)$ & $145600(97060-242600)$ \\
\hline White Salmon River & 1 & 5 & 68 & $0.28(0.18-0.46)$ & $106600(66650-173300)$ \\
\hline Hood River & 1 & 4 & 69 & $0.24(0.14-0.41)$ & $111700(63850-191600)$ \\
\hline Klickitat River & 1 & 13 & 170 & $0.29(0.21-0.41)$ & $95030(67880-131200)$ \\
\hline Deschutes River & $<0.01$ & 0 & 72 & $0.00(0.00-0.00)$ & $0(0-0)$ \\
\hline John Day River & 0.03 & 0 & 34 & $0.00(0.00-0.00)$ & $0(0-0)$ \\
\hline Umatilla River & 0.03 & 0 & 34 & $0.00(0.00-0.00)$ & $0(0-0)$ \\
\hline Walla Walla River & 0.03 & 0 & 34 & $0.00(0.00-0.00)$ & $0(0-0)$ \\
\hline Yakima River & 0.03 & 0 & 34 & $0.00(0.00-0.00)$ & $0(0-0)$ \\
\hline
\end{tabular}

Note: "\# of larvae" is the total number of larval lamprey collected in that tributary river mouth and "\# of drops" is the total number of quadrats sampled by a drop in that tributary river mouth. 


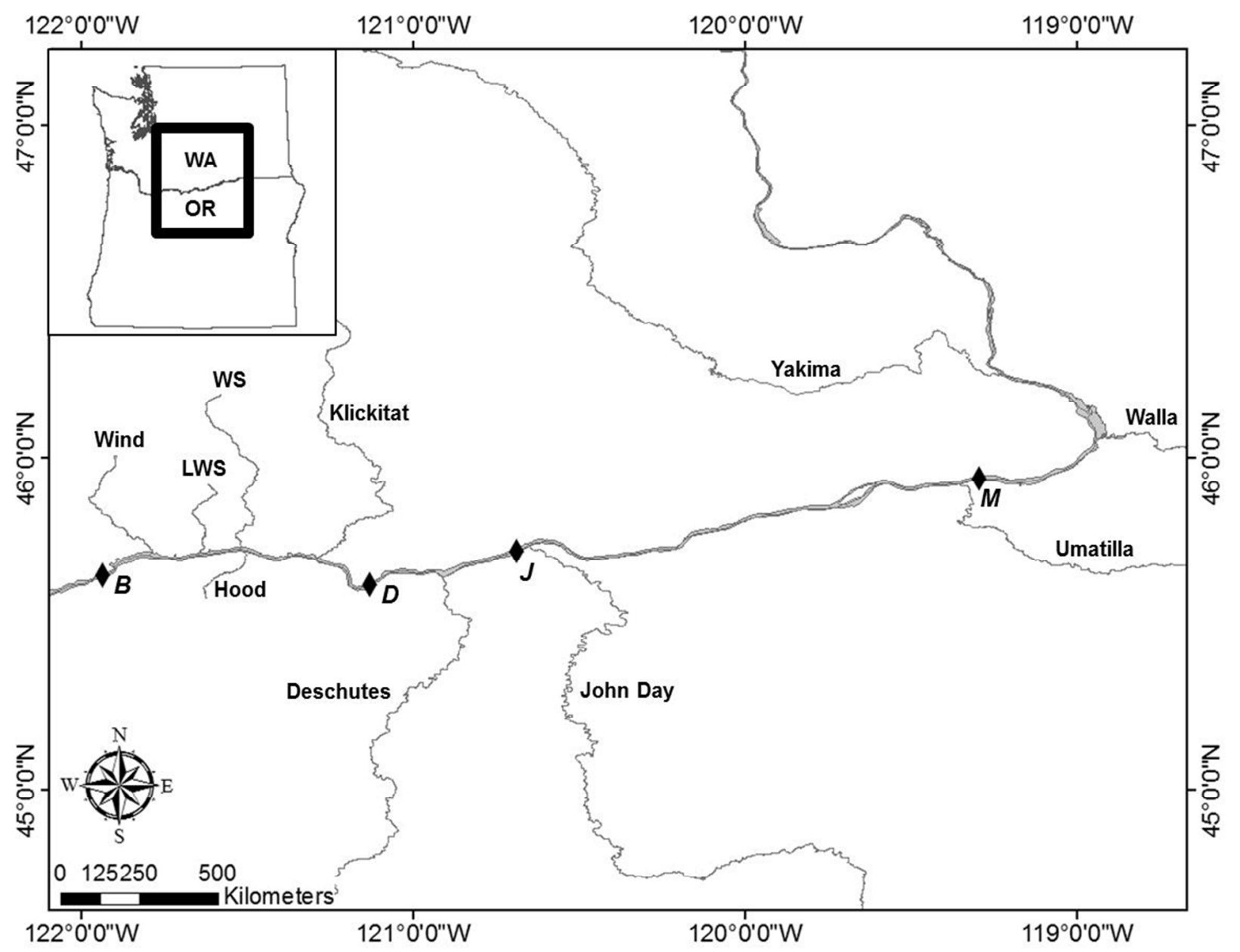

Fig.1. Map of study area in the Columbia River Basin, Washington (WA) and Oregon (OR). The location of each tributary river sampled is shown and indicated ("LWS" = Little White Salmon, "WS" = White Salmon, and "Walla" = Walla Walla) and the location of each dam is indicated by a diamond and letter (" $\boldsymbol{B}$ " = Bonneville, " $\boldsymbol{D}$ " = The Dalles, " $\boldsymbol{J}$ " = John Day, and " $\boldsymbol{M}$ " = McNary). 

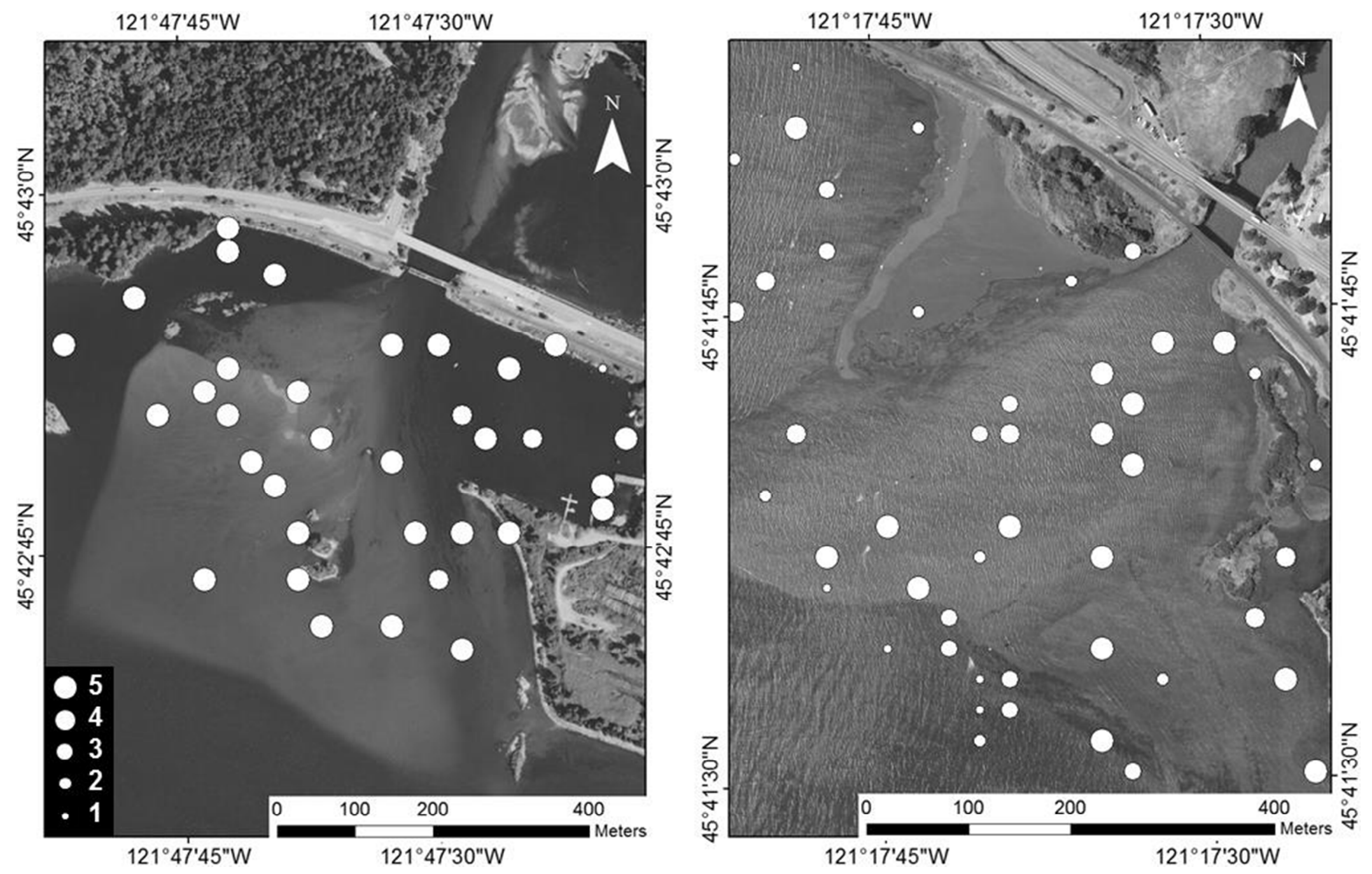

Fig 2. Number of drops completed in each quad (quad located at white circle center) in the Wind (left panel) and Klickitat (right panel) river mouths. 


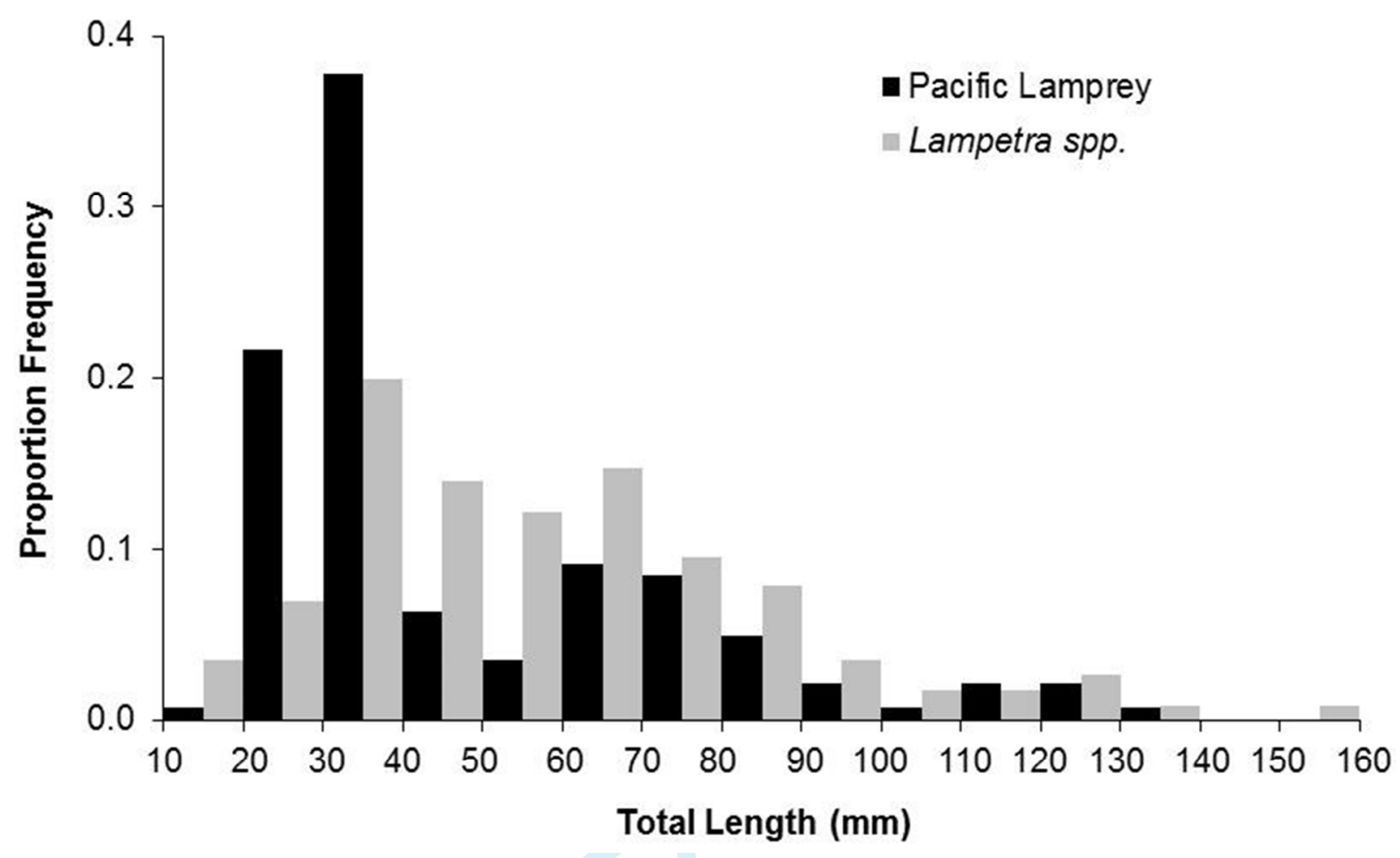

Fig.3. Total length distribution for Pacific lamprey and Lampetra spp. collected in tributary river mouths in the Columbia River basin. 

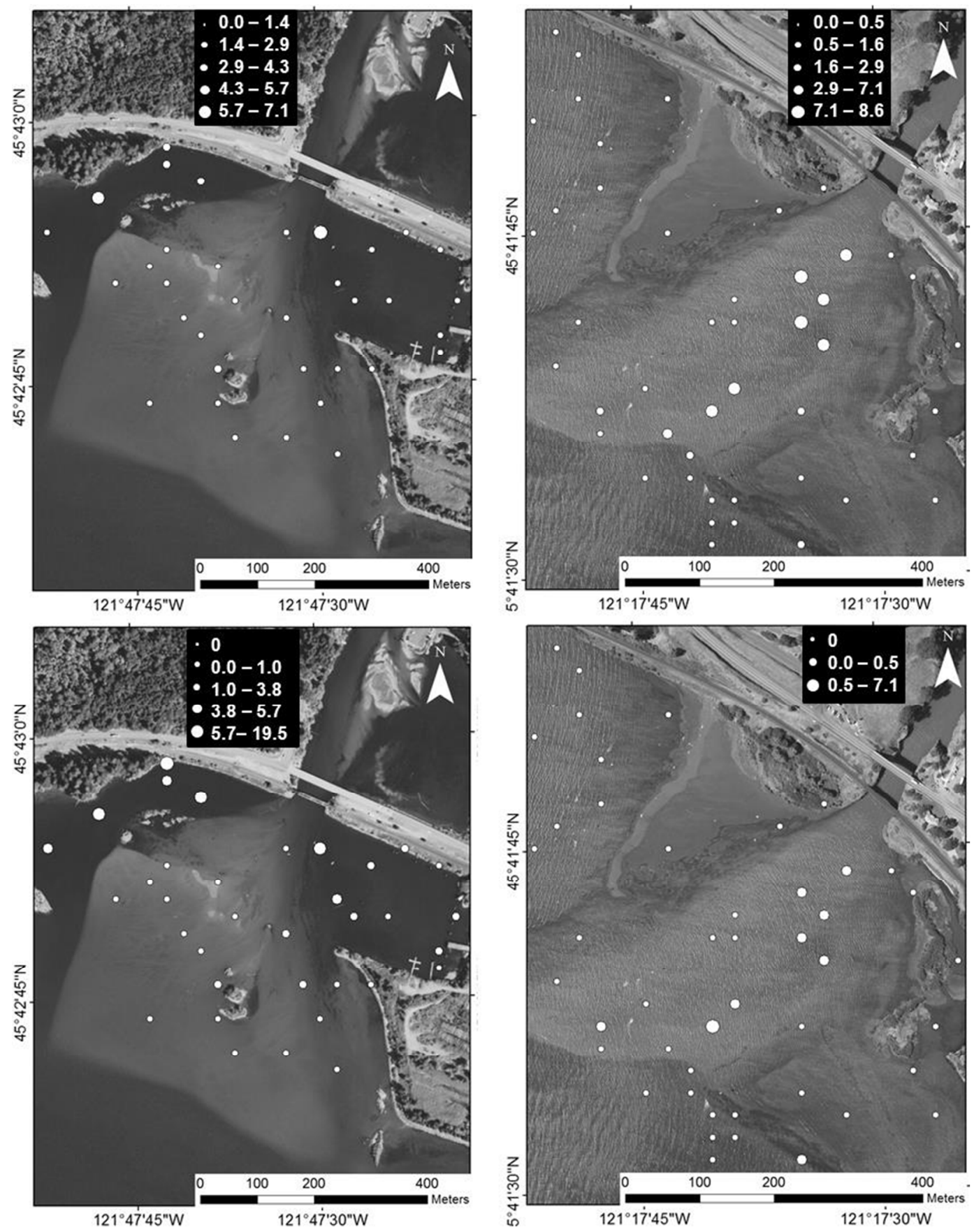

Fig. 4. Average density $\left(\mathrm{m}^{-2}\right)$ for Pacific lamprey (upper panels) and Lampetra spp. (lower panels) estimated by N-mixture models incorporating experimentally-derived estimates of capture probability in the Wind (left panels) and Klickitat (right panels) river mouths. 